
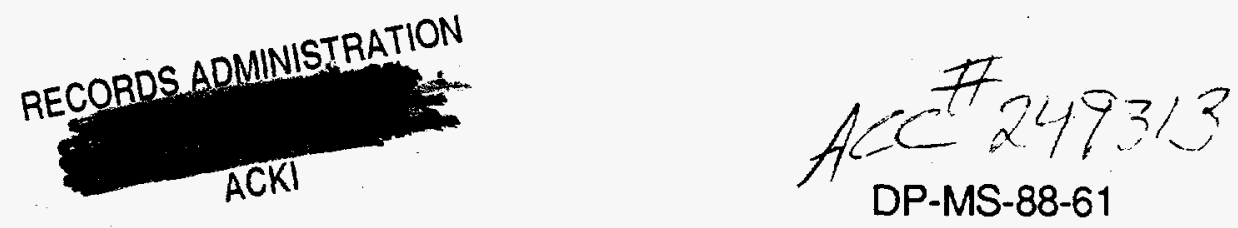

MEASUREMENT OF THE DEPOSITION AND FATE OF $35 \mathrm{SO}_{2}$ IN A PINE PLANTATION*

By

D. W. Gay and Charles E. Murphy, Jr.

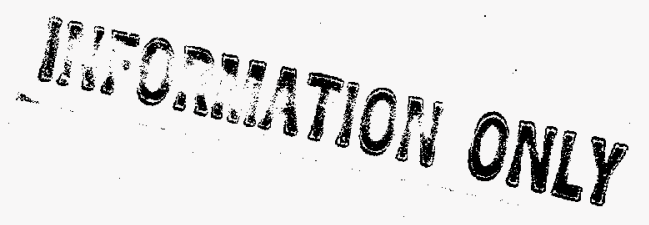

E. I. du Pont de Nemours \& Co.

Savannah River Laboratory

Aiken, South Carolina 29808

RECURO COA

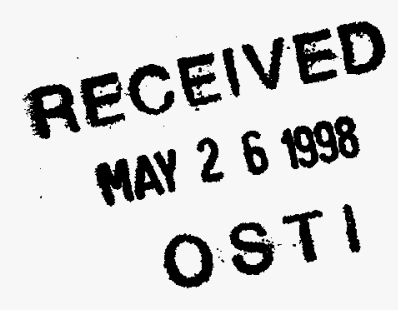

\title{
HASTER PH'
}

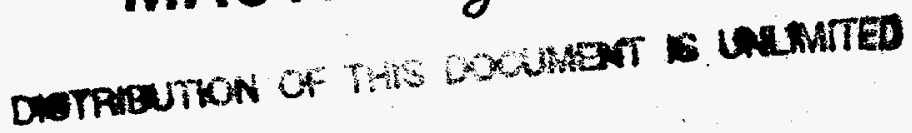

"The information contained in this article was developed during the course of work under Contract No. DE-AC09-76SR00001 with the U.S. Department of Energy. By acceptance of this paper, the publisher and/or recipient acknowledges the U.S. Government's right to retain a nonexclusive, royalty-free licence in and to any copyright covering this paper, along with the right to reproduce and to authorize others to reproduce all or part of the copyrighted paper. 


\section{DISCLAIMER}

This report was prepared as an account of work sponsored by an agency of the United States Government. Neither the United States Government nor any agency thereof, nor any of their employees, makes any warranty, express or implied, or assumes any legal liability or responsibility for the accuracy, completeness, or usefulness of any information, apparatus, product, or process disclosed, or represents that its use would not infringe privately owned rights. Reference herein to any specific commercial product, process, or service by trade name, trademark, manufacturer, or otherwise does not necessarily constitute or imply its endorsement, recommendation, or favoring by the United States Government or any agency thereof. The views and opinions of authors expressed herein do not necessarily state or reflect those of the United States Government or any agency thereof.

This report has been reproduced directly from the best available copy.

Available to DOE and DOE contractors from the Office of Scientific and Technical Information, P.O. Box 62, Oak Ridge, TN 37831; prices available from (615) 576-8401.

Available to the public from the National Technical Information Service, U.S. Department of Commerce; 5285 Port Royal Road, Springfield, VA 22161. 


\section{DISCLAIMER}

Portions of this document may be illegible in electronic image products. Images are produced from the best available original document. 


\section{Abstract}

An experiment was carried out to determine the uptake rate and fate of $\mathrm{SO}_{2}$ absorbed by the forest canopy. The radioactive tracer, $35 \mathrm{~S}$ was used. Branches of loblolly pine were exposed to $35 \mathrm{SO}_{2}$ in the field with a portable chamber. The exposed branches were excised and a sample of needles was immediately washed with distilled water. The needles and water collected in the field was analyzed for ${ }^{35} \mathrm{~S}$ content. The results indicated that a portion of the $35 \mathrm{~S}$ could be washed from the needles and another portion was not removed with a water rinse. The portion that could not be removed by rinsing was absorbed at a rate, and followed patterns of absorption, that suggested that absorption was controlled by stomatal diffusion, and thus was internal. The ${ }^{35} \mathrm{~S}$ that could be removed by rinsing appeared to be surface absorption. The average deposition velocity for the entire leaf surface of the pine plantation was $0.0041 \mathrm{~m} / \mathrm{sec}$.

An analysis of the distribution of $35_{\mathrm{S}}$ by serial extractions

indicated that shortly after internal absorption the $35_{\mathrm{S}}$ was equally distributed between material extracted with acetone, material extracted.with hexane, and material not removed by these two extractions.

Key Words: Sulfur-35, Sulfur Dioxide, Atmospheric Deposition, Forest 


\section{INIRODUCTION}

Smith (1981) has summarized the interaction of air pollutants with vegetation as being of three types. The most striking interaction is the severe damage or death of plants by the action of an air pollutant. However, even when damage is not visible, it is possible that depression of photosynthesis or other types of metabolic processes can negatively affect plants, even leading to a slow decline in vigor or a loss of competitive position in the ecosystem. Finally, there is a level where the pollutant will not harm the plant or in some cases may be beneficial.

Since recognition of the effects of atmospheric deposition on the acidification of watersheds, it has become clear that ecosystem effects of pollutant uptake can be as important as the direct effects on vegetation. At levels that are low enough to cause no apparent direct damage to forest vegetation, there is a potential for $\mathrm{SO}_{2}$ to contribute to acidification of forest soils and runoff from forested watersheds. Near large atmospheric sources of $\mathrm{SO}_{2}$, the absorption of $\mathrm{SO}_{2}$ by forests may be the largest source of sulfur in the watershed sulfur balance. Even at some distance from these sources, the input from $\mathrm{SO}_{2}$ may be nearly as great as the input from "acid rain" (Garland 1977) .

For this reason it is necessary to make accurate estimates of the input of $\mathrm{SO}_{2}$ to forested watersheds and to know how the sulfur 
from this source is redistributed in the forest system. This study investigated some aspects of this problem. Field measurements were made of ${ }^{35} \mathrm{SO}_{2}$ uptake by the needles of pine trees. The deposition velocity of the whole plantation was estimated on the basis of the measured leaf area distribution. The exposed pine needles were analyzed to determine the short term mobility of the of the sulfur absorbed as $\mathrm{SO}_{2}$. The measurements were made at monthly intervals over a one year period to investigate the influence of the change in seasonal climate and phenology on $\mathrm{SO}_{2}$ uptake.

The phytotoxicity of $\mathrm{SO}_{2}$ led to early attempts to measure the uptake rate by vegetation. The advent of the concern for acidification of watersheds has increased interest in this subject. Much of this literature has been reviewed recently (McMahon and Denison 1979, Sehmel 1980, Voldner et al. 1986). While most of the measurements were done on agronomic plants there are nine studies cited in forests. Most of these studies indicate the deposition velocity is between 0.001 and $0.012 \mathrm{~m} / \mathrm{s}$ for daylight periods and $0.0001 \mathrm{~m} / \mathrm{s}$ curing the night. Deposition velocities greater than $0.02 \mathrm{~m} / \mathrm{s}$ have been recorded. The highest values are generally attributed to canopy surfaces wetted by rain or dew. As pointed out by Hick et al. (1980) all of the available measurement techniques have some draw backs and it seems desirable to make and compare measurements by more than one method where possible.

Labeled sulfur has been used to study $\mathrm{SO}_{2}$ uptake (Materna and Kohout 1963, Owers and Powell 1974) and redistribution in the past (Freid 1959, Faller 1972). Most of the $35 \mathrm{SO}_{2}$ experiments also 
dealt with agronomic crops. Among the exception were the studies of Jensen and Kozlowski (1975) and Garland and Branson (1977). The only field study of forest vegetation was that of Garland and Branson. This was also the only study in which the ${ }^{35} \mathrm{SO}_{2}$ method was compared to another measurement technique (Galbally 1979). In this case the results showed quite reasonable agreement between the two measurement techniques. Neither of these studies investigated the seasonal variation in $35 \mathrm{SO}_{2}$ uptake and $35 \mathrm{~S}$ distribution in the plant.

In some experiments the distribution of absorbed $35 \mathrm{~s}$ after absorption was studied (Garsed and Read 1978, Jensen and Kozlowski 1975). It was found that a significant portion of the ${ }^{35} \mathrm{~S}$ absorbed was associated with a water soluble fraction. The distribution between the water soluble fraction and the rest of the absorbed $35 \mathrm{~S}$ varied with environmental conditions. The fate of the internally absorbed $35 \mathrm{~S}$ depended on the time elapsed between exposure and the collection and processing of the sample. In greenhouse grown trees, Jensen and Kozlowski found greater than 95\% of the labelled sulfur in the leaves after the first day. The percentage decreased every day afterwards with some ${ }^{35} \mathrm{~S}$ found in the root water solution after the first day.

$\mathrm{SO}_{2}$ exposures done by Thomas et al. (1944) indicated that the air concentration at exposure (and probably the exposure rate) also influence the partitioning of the absorbed sulfur. If the $\mathrm{SO}_{2}$ concentration was high, a substantial part of the sulfur would remain in the form of dissolved $\mathrm{SO}_{2}$.

In this set of experiments the objectives were to measure the 
uptake rate of ${ }^{35} \mathrm{SO}_{2}$ and the initial distribution of ${ }^{35} \mathrm{~S}$ after exposure in a forest vegetation type. The pattern of redistribution was used to determine the fraction that was easily removed by rain. The distribution of ${ }^{35} \mathrm{~S}$ among the organic fractions within the needles was determined to find out if the sulfur that was absorbed intermally remained in a form that was soluble and could be easily removed later. The experiment was concucted throughout one entire year to determine the extent of the seasonal variation of uptake and redistribution in large, field-grown, forest vegetation.

\section{MEIHODS}

\section{Field Exposure Phase}

A uniform plantation of 15 year old loblolly pine was used for this study. Exposures were made and samples were taken from two different trees each month. Three sampling levels were established between 1.8-3.6 meters, 3.6-5.4 meters, and 5.4-7.2 meters, approximately dividing the crown in thirds. An aluminum scaffold was set up each month between pairs of trees to expose and sample each tree. Four samples were taken from each sampling level for a total of 12 samples per tree with two trees sampled for twelve consecutive months. All pine needles sampled were second year needles.

The exposure chamber consisted of a clear glass $1000 \mathrm{ml}$ widemouthed flask (Figure 2-1). A rubber stopper which fit snugly in the flask had 3 holes drilled through it, one for the inlet tube,

one for the outlet tube and the last for the pine branch. Pine needles were stripped $8 \mathrm{~cm}$ from the end of the branch, and the 
rubber stopper, cut on one radius from the branch hole, was positioned around the pine branch hole. Leakage of air around the hole was restricted with the use of a sealant placed in the branch hole. The inlet tube was a glass $0.64 \mathrm{~cm}$ O.D. tube which extencied to within $1.27 \mathrm{~cm}$ of the bottom of the flask. The outlet tube, glass $0.64 \mathrm{~cm}$ O.D. extended $1.27 \mathrm{~cm}$ through the stopper into the flask. A piece of rubber tubing connected a battery operated portable air pump led to the inlet tube. The air flow was 1 liter per minute. Because of the unique arrangement of the inlet and outlet tubes the air in the exposure flask was thoroughly mixed by bouncing off the sloping side walls toward the rubber stopper where it bounced in the reverse direction.

A $0.64 \mathrm{~cm}$ O.D. plastic "T" was placed in the air inlet line immediately preceding the rubber stopper through which the exposure gas, $35 \mathrm{SO}_{2}$, was introduced via syringe. The exposure syringes used were $2.0 \mathrm{ml}$ gas tight syringes from Precision Sampling Corporation and consisted of teflon parts in precision bored glass barrel assembly. Twelve syringes were loaded with $10-50{ }^{\mathrm{nCi}}{ }^{35} \mathrm{SO}_{2}$ the morning of the field exposures, one syringe for each exposure. The teflon needle housing of the syringe was inserted into the odd arm of the plastic "T" and held in place by a small plastic o-ring. The outlet tube was connected to a $125 \mathrm{ml}$ scrubber flask via a piece of teflon tubing. Twenty-five $m l$ of a $1 \frac{8}{8}$ solution of hydrogen peroxide was used as the scrubbing solution.

To minimize the build up of transpired water and heat inside the 
exposure flask, a 3 minute exposure period was used. The contents of the $2.0 \mathrm{ml}$ exposure syringe was slowly injected into the air stream over 3 minutes. An additional 1 minute flow of air was used to flush remaining $35 \mathrm{SO}_{2}$ from the flask and into the scrubbing solution.

After the 4 minute air flow period, the flow of air was terminated and the branch tip entering the exposure flask was immediately severed from the branch. The exposure flask with enclosed branch tip was lowered to the ground where the branch tip was removed. Two 20 fascicle samples were removed from the tip. One sample of needles was cut into two pieces and placed in a glass tube to which liquid nitrogen was immediately added. The tube was then sealed and placed in dry ice for subsequent transport to the laboratory for further preparation. The other sample was also cut into two pieces and placed in a like glass tube which contained $10 \mathrm{ml}$ of deionized water. The needles were slowly agitated in the deionized water for 10 minutes. A $2 \mathrm{ml}$ aliquot of water was then removed from the tube and placed in scintillation vial. This was the field rinse subsample.

At the completion of each day's exposure and sampling, 12 vials of needles frozen in liquid nitrogen, 12 scrubbing flasks, 12 field rinse vials with needles and 12 subsamples of $10 \mathrm{ml}$ deionized water field rinse in liquid scintillation vials were taken to a laboratory for further preparation. Two $\mathrm{ml}$ aliquots of scrubbing solution from each flask were removed and placed in liquid scintillation vials.

\section{Laboratory Sample Preparation}


As soon as all subsamples were brought to the laboratory, the vials of liquid nitrogen frozen needles were immediately placed in a freezer and stored there until processed. The initial processing consisted of removing a vial of frozen needles from the freezer, allowing the needles to warm up for 10 minutes and then adding 10 $\mathrm{ml}$ of deionized water to the vial. The cap was replaced and the vial slowly agitated for 10 minutes as was done for the field rinsed samples. A $2.0 \mathrm{ml}$ aliquot of rinse water was removed and placed in a liquid scintillation vial. The remaining lab rinse water was decanted into a clean vial, the needles were removed and spread out on paper towels and were patted dry with fresh paper towels. The dried needles were then weighed. This weight was used as the fresh weight for all calculations. The needles were then cut into small pieces (1 - $1.5 \mathrm{~cm}$ in length) into a mortar pre-chilled with liquid nitrogen. They were ground into a fine dry powder in liquid nitrogen with a pre-chilled pestle (Zeisler et al. 1983). Aliquots of liquid nitrogen were dispensed into the mortar to maintain the frozen dry nature of the ground tissues until a fine powder was obtained. A subsample of this frozen powder (approximately $0.5-1.0 \mathrm{gm}$ ) was inmediately placed in a pre-weighed vial and weighed. The powder and cup were then combusted.

From the frozen powder remaining, another aliquot, approximately 2.0 grams, was placed in a pre-weighed vial and weighed. The remaining powder, if any, was sealed in a vial and placed in the freezer for subsequent use if any material was lost in succeeding steps of the procectures. 
To the vial containing the subsample of frozen powder, a $15 \mathrm{ml}$ aliquot of reagent-grade acetone was added and the vial and powder were slowly shaken on a mechanical shaker for 30 minutes. The mixture was decanted into Whatman 41 filter paper in a funnel and the filtered liquid was trapped in another vial. The sample was allowed to drain for 30 minutes for adequate filtration and partial drying of the trapped residue on the filter paper, the acetone containing vial was replaced with an empty vial and $13 \mathrm{ml}$. of reagent grade hexane were added to the resicue and filtered through. Excess hexane was carefully pressed out of the resicue with a glass stirring rod and the residue was allowed to dry an additional 30 minutes. The vial containing the original acetone filtrate was placed under the funnel and the partially dried resicue was rinsed with approximately $3 \mathrm{ml}$. of fresh acetone. After partial air drying again, the residue was scraped onto a clean filter in a Buckner funnel attached to a vacuum pump. The resicue was thoroughly dried and all acetone vapors were removed after about one hour. When dry, the powder was pressed into a pellet, weighed and combusted.

The acetone and hexane fractions were recuced in volume by passing a directed airstream over them. The hexane was taken to dryness with the subsequent addition of $0.5 \mathrm{ml}$ of $1 \mathrm{~N} \mathrm{NaOH}$ to the vial. The cap was replaced and the vial was agitated for about 5 minutes to take up resictual material. The acetone layer was similarly recuced in volume to the water remaining which the acetone extracted from the tissues. This water layer (approximately 2 ml.) was further recuced to $1 \mathrm{ml}$. 
The residual water fraction in the acetone and the $\mathrm{NaOH}$ solution from the hexane extract were prepared for combustion in the following manner. Whatman 41 ashless filter paper was cut into approximately 8 Imm squares and a combustion cup was approximately $2 / 3$ filled with these squares. The remaining liquid in each extract was pipetted onto the filter papers in separate combustion cups. Any residual material in these vials was removed by wiping the inside and bottom of each vial with fresh $8 \mathrm{~mm}$ squares of filter paper. These wipes were then added to the appropriate combustion cup. The transfer of material was virtually complete using this procecure.

Combustion was used to separate the $35 \mathrm{~S}$ for counting (Grundon and Asher 1972). The combustion furnace consisted of a quartz tube $65 \mathrm{~cm}$ long with an outside diameter of $3.2 \mathrm{~cm}$ inside a temperature controlled oven maintained at 525-550 ${ }^{\circ} \mathrm{C}$. Both argon and oxygen gases were metered into the furnace. Inside the quartz tube were placed a $5 \mathrm{~cm}$ bed of oxidized copper wire, supported on quartz wool, and a $5 \mathrm{~cm}$ bed of broken quartz pieces. The gases entered the quartz tube from a small side tube outside the heated area which was attached near the top of the quartz tube and exited the quartz tube through a small condensation coil attached to the larger quartz tube via a $12 / 5 \mathrm{ball}$ and socket arrangement. A cap for the quartz tube was made from a $35 / 25$ socket which fit onto the ball assembly fused to the top of the column. Spring clamps held both assemblies together. Silicon grease was applied to each assembly to maintain an air-tight configuration.

The following procecture was used to combust the samples. Argon 
flow was adjusted to $2.5 \mathrm{l} / \mathrm{min}$., the cap removed from the quartz tube, and the sample dropped into the furnace region with the cap replaced immediately. The argon flow was decreased to zero liters per minute while the oxygen flow was increased to 2.5 liters per min. The combustion of the sample could be observed because of the orange glow of the burning sample transmitted through the quartz walls. When the glow was extinguished, the oxygen flow was continued 1 minute longer, after which the oxygen flow was decreased while the argon flow increased until $100 \%$ argon was going through the tube. The gaseous effluent from the combustion process passed down through the quartz tube into the small condensation coil which was designed to fit inside a liquid scintillation vial. The vial contained $7 \mathrm{mi}$. of a trapping solution $\left(2 \mathrm{ml}\right.$. of $1 \% \mathrm{H}_{2} \mathrm{O}_{2}$ and $5 \mathrm{ml}$ of liquid scintillation cocktail) and was kept in an ice bath to hasten condensation and subsequent entrapment of gases in the trapping solution in the vial. After the combustion of the sample, the coil was removed from the quartz tube and $14 \mathrm{ml}$. of liquid scintillation cocktail was rinsed through and over it into the vial.

Aliquots of $2 \mathrm{ml}$. were taken from all aqueous samples, i.e. field rinse, lab rinse and scrubbing solution, and placed in liquid scintillation vials to which $19 \mathrm{ml}$. of liquid scintillation cocktail was added. The combusted samples contained $7 \mathrm{ml}$. of a trapping mixture to which $14 \mathrm{ml}$. of liquid scintillation cocktail was added.

All samples were counted in a Beckman Liquid Scintillation Counter. Because of the elevated $3_{\mathrm{H}}$ (tritium) background in the pine needles, due to ${ }^{3} \mathrm{H}$ releases from some facilities on site, a channel 
for $3_{\mathrm{H}}$ was counted for each sarple and subtracted from the wide band channel used to count the ${ }^{35} \mathrm{~S}$. Comparable aliquots of ${ }^{35} \mathrm{SO}_{2}$ as used for the exposures were withdrawn at the same time as the exposure aliquots and were used as standards. All counting was corrected for decay. Blanks were used to detemine background radiation and were subtracted from the sample counts.

The ${ }^{35} \mathrm{SO}_{2}$ material was supplied by New England Nuclear at a specific activity of $10 \mathrm{Ci} / \mathrm{M} \mathrm{mol} \mathrm{with} 1 \mathrm{~m} \mathrm{Ci}$ supplied quarterly in a $25 \mathrm{ml}$ refrigerated container. our use of $\mathrm{nCi}$ amounts of ${ }^{35} \mathrm{SO}_{2}$ for each exposure introcuces amounts of $\mathrm{SO}_{2}$ in the subnanogram range in the plants.

\section{RESULTS}

Inspection of the data collected for the 288 exposures indicated a very low recovery of the administered ${ }^{35} \mathrm{~S}$. Since the ${ }^{35_{S}}$ on the chamber walls was not measured and it is not possible to estimate the entire activity taken up by the pine branches, only a rough estimate can be made of the activity taken up by the chamber. Table I shows the estimated average chamber uptake for all the exposures under the assumption that the absorbing surface area of the entire branch in the chamber is three time the area of the needle fascicles sampled. Approximately $80 \%$ of the activity was removed by the chamber walls. This is in agreement with the results of Garsed and Read (1977) where more than $90 \%$ of the activity was removed by a glass walled chamber system.

Table II presents a summary of the entire data set. Each value 
is the average of the twelve branches exposed, four at each of three levels. The average total specific activities and their standard deviation indicate the type of variation found in the data. Some of the variation between sample days is caused by differences in the magnitude of the exposure due to decay of the exposure source over the three month period in which the same source was used. The table also shows the partitioning of the total absorbed activity between the measured needle fractions. This data was analyzed to determine 1) the relationship between sulfur that could be washed off of the needles versus that absorbed internally, 2) the distribution of sulfur among internal needle fractions immediately after uptake, and 3) the deposition velocity and resistances to $\mathrm{SO}_{2}$ uptake which were used to estimate whole forest uptake of $\mathrm{SO}_{2}$.

\section{Comparison of Rinse Activity with Incorporated Activity}

A number of investigations have been made which indicate that rainfall collected under the forest canopy is enriched in sulfur (Mayer and Ulrich 1978, Shriner and Henderson 1978). In some cases the enrichment has been interpreted as the dry fall of sulfur

compounds accumulated between rainfall periods (Lovett and Iindberg 1984). The role of absorption of $\mathrm{SO}_{2}$ between rainfall periods in the enrichment is uncertain. This part of the study was designed to assess what part of the $\mathrm{SO}_{2}$ absorbed would be immediately available for leaching from the canopy.

During the first three months of the data collection, the 
needles were washed in the laboratory immediately after transport from the field site. This procedure was later questioned because of the possible damage to the integrity of the needles following quick freezing in the field. To ascertain if the rinse performed in the laboratory was comparable to rainfall removal, a field rinse procedure was initiated. Two samples of 20 fascicles each were removed from the exposed branch tip. One of which was rinsed with deionized water. An aliquot of the rinse water was removed for later liquid scintillation counting. The remaining sample was frozen and analyzed in the same manner in the laboratory.

The results of this experiment show that the activity washed from the samples in the field is nearly identical with the activity removed by the laboratory rinse in most cases. The mean ratio of the laboratory to field was 0.997 with a standard deviation of the mean of 0.202 . This suggests that the structural integrity of the pine needles is maintained as far as the activity of ${ }^{35} \mathrm{~S}$ incorporated from labelled $\mathrm{SO}_{2}$ is concerned.

Since the adequacy of the laboratory rinse has been sustained, it is appropriate to look at the relationship of the activity removed by rinsing to the activity remaining after the rinse for all twentyfour trees. A plot of the ratio of activity in the needles after rinsing divided by the activity removed by rinsing is shown in Figure 1. A clear seasonal trend is evident. At all levels in the canopy, there is a relative decrease in the activity remaining after rinsing during the summer months. This trend is most pronounced in the needles in the upper and middle part of the canopy. At the lowest 
level in the canopy the summer decrease in the ratio is not as great.

The annual trend in this ratio follows the documented pattern of the transfer of water vapor and carbon dioxide in this pine plantation (Murphy 1985). Mass transfer between the inside of the needles and the atmosphere is limited by stomatal closure during the hot, and often dry, summer months. This suggests that it is probably justified to associate most of the rinsed activity with the surface of the needles and most of the remaining activity with internally absorbed $\mathrm{SO}_{2}$ that must pass through the stomata.

The observation that the seasonal trend is not as pronounced deeper in the canopy is consistent with the finding of Gresham (1975) that the stoma of the shaded lower canopy needles of loblolly pine are very sluggish in their response to environmental stimuli.

\section{Comparison of $35 \mathrm{~S}$ in Needle Fractions}

The fractionation procecture, described in the Methods section, was devised to determine the class of materials that $\mathrm{SO}_{2}$ is partitioned to after uptake. This information can be used to determine the availability of sulfur for rain washout of the needles. The three fractions resulting from this procedure were the acetone fraction, the hexane fraction, and the tissue fraction. The acetone rinse selectively extracted the chloroplast-chlorophyll materials along with the less lipophilic components. The hexane fraction includes the more lipophilic materials. The tissue fraction was the cellular material remaining after the solvent extractions and 
contained cell walls and associated structural materials. The analyses were done on subsamples of the needles frozen in liquid nitrogen immediately after collection in the field. The results of the analyses are summarized in Table II, as the percent of the total internally absorbed activity averaged for all branches in each tree. The specific activity in each fraction for any tree can be calculated by multiplying the fraction of the activity in the extraction times the fraction of activity in the dry material, and then multiplying this fraction times the total specific activity.

In most cases, approximately $33 \%$ of the activity resides in each extracted fraction. Three trees that deviate from the pattern seen in the other trees. One of the trees exposed in March has a higher level of activity in the hexane fraction. In both April and May one of the two trees exposed curing the month has more activity in the residual material. In all cases the deviation is consistent at more than one level in the canopy. However, the companion tree exposed curing the same month show the same, roughly equal, partition between the three fractions found in all other trees.

\section{Transfer Resistances and the Deposition Velocity for ${ }^{35} \mathrm{SO}_{2}$}

The deposition velocity is a simple normalizing of the uptake by the concentration of $\mathrm{SO}_{2}$ in the atmosphere. Meteorological models using constant deposition velocities for particular vegetation types have been used to make approximations of vegetation uptake (Sheih et al. 1979) . 
A somewhat more sophisticated model is the resistance model of gas transfer which attempts to isolate the effects of diffusion and metabolic processes by using the analogy of an electrical network (Raschke 1956, Bennett et al. 1973). Both of these approaches can be improved by allowing the parameters of the model, the deposition velocity or the resistances, to vary with the physiological and environmental forces which affect the processes which they describe. An important example of this is to make the resistance to internal uptake vary with the environment surrounding the vegetation. The resistance to internal uptake is often dominated by the diffusion of the gas through the stoma on the leaf surface. These small pores open and close in response to light, temperature and other environmental stimuli (see Jarvis and Mansfield 1981 for a collection of papers on this subject).

By definition the total deposition velocity $\left(v_{d}\right)$ is calculated by:

$$
\mathrm{v}_{\mathrm{d}}=\mathrm{F}_{\mathrm{v}} /\left(\mathrm{A}_{\mathrm{v}} \mathrm{C}\right)
$$

The deposition velocity is the needle uptake $\left(F_{\mathrm{V}}\right)$ per unit surface area (A) divided by the mean concentration (C). The definition of the mean air concentration churing the exposure is complicated by the depletion of the ${ }^{35} \mathrm{SO}_{2}$ by the chamber walls and the vegetation. However, it is possible to calculate a deposition velocity for the vegetation if we are willing to accept the assumption that the 
absorption by the chamber walls can also be defined by a deposition velocity for the walls $\left(v_{d w}\right)$. It is also necessary that the same average concentration used to calculate the vegetation uptake can be used to calculate the wall deposition.

Under these conditions, the change in the flux of ${ }^{35} \mathrm{SO}_{2}$ as it passes through the chamber is balanced by the flux to the walls $\left(E_{W}\right)$ and the vegetation $\left(E_{V}\right)$. The deposition fluxes are a function of their respective deposition velocities and surface areas.

$$
\mathrm{dF} / \mathrm{dt}=-\left(E_{\mathrm{V}}+E_{\mathrm{W}}\right)=-\left(v_{d} A_{\mathrm{V}}+v_{d w} A_{W}\right) C=-a C
$$

The combination of the sinks for ${ }^{35} \mathrm{SO}_{2}$ defines the chamber system uptake factor (a). Equation (2) can be redefined in terms of concentration and the volume of air containing the ${ }^{35} \mathrm{SO}_{2}$.

$$
\mathrm{dC} / \mathrm{C}=-\mathrm{a} \mathrm{dt} / \mathrm{V}
$$

If this equation is solved with the boundary condition, at $t=0$ then $C=C_{i}$, and at the time $t=t_{0}$ where $C=C_{0}$ then

$$
C_{O} / C_{1}=\exp \left(-a t_{O} / V\right)
$$

where the subscripts $i$ and o refer to the input and output of the chamber system. Equation (4) is equivalent to

$$
F_{0} / F_{i}=\exp \left(-a t_{0}\right)
$$

Since we also know $F_{i}-F_{0}=F_{V}+F_{W}=a C$, then

$$
C=\left[\left(F_{O}-F_{i}\right) t_{0}\right] /\left[\ln \left(F_{O} / F_{i}\right)\right]
$$

and

$$
\left.v_{d}=F_{v} \ln \left(F_{O} / F_{i}\right)\right] /\left[A_{v}\left(F_{O}-F_{i}\right) t_{0}\right]
$$

In summary, if we know the total activity entering the chamber, the total activity left at the exit, the activity in the vegetation per unit surface area $\left(\mathrm{F}_{\mathrm{V}} / \mathrm{A}_{\mathrm{V}}\right)$, and the chamber through-put time $\left(t_{0}\right)$ 
we can calculate the deposition velocity for the vegetation without knowledge of any other chamber characteristics. The results of this calculation is sumarized by tree in Table III.

The transfer resistance for ${ }^{35} \mathrm{SO}_{2}$ into the needle can be calculated using a model, similar to the one above, to partition the surface absorption and the internal $35_{S}$ uptake. The external air concentration used in the calculation is the one defined in the previous calculation.

This model describes the uptake path as diffusion through the aerodynamic boundary layer of the needle followed by partitioning of the gas into a flux absorbed by the needle surface and a flux which diffuses into the leaf. The equation describing this model has two unknowns, an aerodynamic resistance and an internal leaf resistance. Fortunately, the magnitude of the aerodynamic resistance is set by the size and shape of the needle and the wind speed. Since the wind speed is constant in the chamber and the size and shape of the needles do not vary greatly, it is possible to calculate the aerodynamic resistance on the basis of an engineering heat transfer formula. For the conditions of our experiments the value is about 6 $\mathrm{sec} / \mathrm{cm}$ for the gas $\mathrm{SO}_{2}$ (Monteith 1973).

Once the aerodynamic resistance $\left(r_{a}\right)$ is estimated, the leaf resistance to internal uptake can be calculated from the equation

$$
r_{i}=C / F_{i n}-\left(E / E_{i n}\right) r_{a}
$$

The $\mathrm{SO}_{2}$ activity of the air (C) is the average value of the air 
entering and leaving the chamber. The ratio of the internal flux absorbed $\left(F_{i n}\right)$ and the total flux absorbed $\left(F_{V}\right)$ are known from the ratio of activity of the samples in the rinse water and the vegetation after rinsing. The results of these calculations are shown in Table III. The standard error of the calculated resistances is large. This is because large changes in the resistances are generated by small changes in the reciprocal of the small uptake numbers.

\section{Effect of the Environment on ${ }^{35} \mathrm{SO}_{2}$ Uptake}

An attempt was made to correlate the uptake and distribution of $35 \mathrm{SO}_{2}$ with the local environment. In terms of the model used to describe uptake, there are two parameters which could vary with environment, the aerodynamic and the leaf resistances. As discussed previously, the chamber artificially limits the range of aerodynamic resistance experienced in these experiments. Therefore the experiments can not be used to determine the effect of environmental variation on this resistance. However, Dollard (1980) has shown that uptake is not greatly affected by changes in wind speed through the range normally encountered in species with needle-shaped leaves.

For internal uptake the leaf resistance is the dominant factor limiting uptake. The leaf resistance can be described in terms of two components, a resistance to diffusion through the stoma to the wet internal cell walls and a resistance to diffusion through the cell wall and the cell to the site of absorption. For very low $\mathrm{SO}_{2}$ concentration, such as those experienced in this experiment, the stomatal resistance is the dominant factor limiting uptake 
(Martin and Barber 1971). In this case, one would expect the leaf resistance to respond to the same environmental factors which affect stomatal aperture, i. e. light, temperature, and water stress.

An analysis of multiple covariance (SAS 1982) was used in an attempt to determine if there were statistically significant effects of canopy position, temperature or water vapor density deficit on the stomatal resistance. Temperature and humidity were the only parameters consistently measured throughout the entire period of the experiment. The results showed very poor correlation with these variables.

The same analysis was applied to the period of August to Eebruary of the following year when solar radiation was measured immediately above the exposed branch. This analysis showed significant effects for canopy level and a marginal effect of air water vapor density deficit. A Duncan's range test for the effect of the treatment, level in the canopy, indicates that the upper two levels are not significantly different from each other but both of the upper levels are different from the lower level. This is in agreement with an analysis of photosynthesis in a similar loblolly pine canopy (Higgenbotham 1974) .

\section{DISCUSSION}

Several compilations of the vegetation $\mathrm{SO}_{2}$ deposition velocity have been published (McMahon and Denison (1979), Sehmel 1980, and Voldner et al. 1986). Deposition velocities in the range of 0.001 to 
greater than $0.02 \mathrm{~m} / \mathrm{s}$ are cited for forests. The lowest values are near the limits of detectability for most of the measurement systems while most of the highest values are associated with a wet canopy. Deposition velocities for daylight periods are generally in the range from 0.004 to $0.01 \mathrm{~m} / \mathrm{s}$ when the canopy is dry.

Three studies of $\mathrm{SO}_{2}$ deposition to forests provide a more detailed look at the magnitude and patterns of $\mathrm{SO}_{2}$ deposition. Fowler and Cape (1982) found daylight deposition velocities in the range of 0.02 to $0.01 \mathrm{~m} / \mathrm{s}$ in a Scots pine stand. Night deposition velocities were lower, in the range of 0.0001 to $0.002 \mathrm{~m} / \mathrm{s}$ for a dry canopy and up to $0.004 \mathrm{~m} / \mathrm{s}$ for a wet canopy. Johansson et al. (1982) found values in the range of 0.001 to $0.0035 \mathrm{~m} / \mathrm{s}$ in conifers during the winter. Lorenz and Murphy (1985) found daytime values of $\mathrm{SO}_{2}$ deposition velocity that varied from less than the sensitivity of the measurement system, about 0.002 , to $0.02 \mathrm{~m} / \mathrm{s}$. The results of this last study is of particular interest because it was made one year earlier on the same loblolly pine plantation as the measurements in this paper.

A comparison between the ${ }^{35} \mathrm{SO}_{2}$ uptake of branches in this paper and the gradient measurements taken earlier can be made by taking the leaf deposition velocity and multiplying by the leaf area per unit ground area in the stand. An extensive study of leaf area in this plantation indicates that leaf area index (all leaf surfaces) is close to six in the winter. The winter value will be doubled by early October just before needle fall. Using these values of leaf area index the annual average deposition velocity for the loblolly 
pine stand was $0.0041 \mathrm{~m} / \mathrm{s}$. The average value from the gradient measurements was $0.0072 \mathrm{~m} / \mathrm{s}$.

Figure 2 shows the month to month variation in deposition velocity measured by both techniques. The measurements were made in consecutive years, the ${ }^{35} \mathrm{SO}_{2}$ measurements in the year following the gradient measurements. The agreement between measurements is quite good when one considers the large variation in individual measurements by both methods. In both cases, the variation is not an indication of experimental error but a reflection of the real variability of deposition velocity as affected by the local climate, and tree to tree or branch to branch variations.

The stomatal resistance to $\mathrm{SO}_{2}$ measured in this study can also be compared to earlier studies of stomatal resistance determined from water vapor transport in this same stand. In these studies a nonlinear regression model was developed to estimate average stomatal resistance from a knowledge of the physical environment. The average stomatal resistance was found to be predicted with reasonable accuracy by a function of temperature, air water vapor density deficit, and solar radiation (Murphy 1985).

Table III shows a comparison of the results of the calculation of stomatal resistance from the ${ }^{35} \mathrm{SO}_{2}$ exposures and the values computed for the conditions of the day on which measurements were made. The resistance to water vapor transfer was multiplied by 1.88 to account for the difference in the molecular diffusivities of water vapor and $\mathrm{SO}_{2}$. The results are reasonably good for most of the exposure periods. However, the model does not predict the very high 
resistances measured by the ${ }^{3} 5_{\mathrm{SO}_{2}}$ exposures during June. It is possible that this is caused by the fact that the model does not account for the effect of soil moisture stress. Although the effect of soil moisture is usually small in forests in the humid climate of the southeastern U. S., it can be significant during some periods.

\section{Canciustons}

The results of the measurements of ${ }^{35} \mathrm{SO}_{2}$ uptake by loblolly pine branches are in agreement with aerodynamic measurements of $\mathrm{SO}_{2}$ uptake made in the same stand. The results are consistent with the hypothesis that internal uptake is limited by diffusion through the stoma on the leaf surface.

Absorption on the leaf is about equally distributed between material that can be washed off the leaf and material that can not be easily removed. Unfortunately it is impossible to determine the capacity of the leaf for surface absorption from the short term exposures done in this experiment. Dollard (1980) found similar or even higher surface absorption but quoted Horntvedt (1977) that in exposures of a few days the surface uptake was a smaller fraction of total uptake indicating that saturation was occurring during this period. At parts per billion levels of $\mathrm{SO}_{2}$ exposure, Johansson et al. (1982) found that deposition to branches was higher than could be explained on the basis of stomatal resistance. This is also consistent with absorption by the external surfaces of the branch. 
The extent of surface uptake is important. Saturation of the surfaces should occur but it is also possible that the surfaces are renewed by washing with rain. If the time taken to saturate the surfaces is small compared to the time between rains then the surface uptake can be ignored on the average, otherwise it may be a significant sink for sulfur. Fowler and Unsworth (1979) have shown that, even when the stomata are fully opened, as much as $30 \%$ of the $\mathrm{SO}_{2}$ absorbed on wheat may be on the external surface of the leaves. They estimate that the surface absorption averages about $50 \%$ of the entire uptake.

once $35 \mathrm{~S}$ is internally absorbed through the leaf stoma, it is incorporated into a variety of leaf compounds. The distribution is about equally divided between chloroplast-chlorophyll materials, the more lipophilic materials extracted by hexane, and the structural material left after extraction. These materials are not easily washed from the leaf. 


\section{REEERENCES}

J. H. Bennett; A. C. Hill, and D. M. Gates. 1973. A model for gaseous pollutant sorption by leaves". J. Air Pollution Control Assoc. Vo1. 23:957-962.

G. J. Dollard. 1980. Wind Tunnel Studies on the Dry Deposition of ${ }^{35} \mathrm{SO}_{2}$ to Spruce, Pine and Birch Seedlings." Intern Rapport IR $\underline{54 / 80}, 37 \mathrm{p}$.

N. Faller. 1972. Absorption of sulfur dioxide by tobacco plants differentially supplied with sulphate. In Isotopes and Radiation in Soil-Plant Relationships Including Forestry. IAEA, Vienna, p. 51.

D. Fowler and J. N. Cape. 1982. Dry deposition of $\mathrm{SO}_{2}$ onto a scots pine forest. Precipitation Scavenging, Dry Deposition and Resuspension. Pruppacher et al. Eds. Elsevier Pub. Co., Pp. 763-774.

D. Fowler and M. H. Unsworth. 1979. Turbulent transfer of $\mathrm{SO}_{2}$ to a wheat crop. Quart. J. Roy. Met. Soc., Vol 105:767-783.

M. Freid. 1959. The absorption of sulfur dioxide shown by the use of radioactive sulfur. Soil Sci. Soc. Amer. Proc. Vol. 13:135-138.

I. E. Galbally, J. A. Garland and M. J. G. Wilson. 1979. Sulphur uptake from the atmosphere by forest and farmland. Nature Vol. 280: 49-50.

J. A. Garland. 1977. Dry deposition of $\mathrm{SO}_{2}$ to land and water surfaces. Proc. R. Soc. London. Series A, Vol 354:245-268.

J. A. Garland and J. R. Branson. 1977. The deposition of sulphur dioxide to pine forest assessed by a radioactive tracer method.

Tellus. Vol. 29:445-454.

S. G. Garsed and D. J. Read. 1977. The uptake and metabolism of $35 \mathrm{SO}_{2}$ in plants of differing sensitivity to sulphur dioxide. Environmental Pollution. Vol. 13:173-186.

C. A. Gresham. 1975. Stomatal resistance in a loblolly pine plantation. Ph. D. Dissertation, Duke University. Durham, North Carolina, USA, $172 \mathrm{p}$.

N. J. Grundon and C. J. Asher. 1972. Improved method of sulfur-35 in plant material using oxygen flask combustion and liquid scintillation counting. J. Agr. Food Chem., Vol. 4:794-798.

B. B. Hicks, M. L. Wesely, J. L. Durham. 1980. Critique of methods to measure dry deposition: Workshop Summary, EPA-600/9-90-050, Research Triangle Park, N.C. 
K. O. Higgenbotham. 1974. The influence of canopy position and the age of leaf tissue on growth and photosynthesis in loblolly pine." Ph. D. Dissertation, Duke University. Durham, North Carolina, USA, $248 \mathrm{p}$.

R. Horntvedt. 1977. Exposure chamber study of $\mathrm{SO}_{2}$ deposition on spruce seedlings. Presented at Workshop Meeting to Consider Methods Involved in Studies of Acid Precipitation to Eorest Ecosystems. Edinburgh, U. K., 19-23 September 1977.

P. G. Jarvis and T. A. Mansfield. 1981. Stomatal Physiology. Cambridge University Press. London. $295 \mathrm{p}$.

K. F. Jensen and T. T. Kozlowski. 1977. Absorption and translocation of sulfur dioxide by seedlings of four forest tree species. J. Environmental Quality. Vol. 4:173-186.

C. Johansson, A. Richter and I. Granat. 1982. Dry deposition on coniferous forest of SO2 at PPB levels. precipitation Scavenging, Dry Deposition and Resuspension. Pruppacher et al. Eds. Elsevier Pub. Co. 1982, PP. 763-774.

R. Lorenz and C. E. Murphy Jr. 1985. The dry deposition of sulfur dioxide on a loblolly pine plantation. Atmospheric Environment. Vol. 19:797-802.

G. M. Lovett and S. E. Lindberg. 1984. Dry deposition and canopy exchange in mixed oak forest as determined by analysis of throughfall. J. Appl. Ecol. 21:1013-1027.

J. Materna and R. Kohout. 1963. The absorption of sulfur dioxide by spruce and pine trees. Naturwissenschften Vol 50:407.

A. Martin and E. R. Barber. Some measurements of loss of atmospheric sulphur dioxide near foliage. Atmospheric Environment. Vol. 5: 345-352.

R. Mayer and B. Ulrich. 1978. Input of atmospheric sulfur by dry and wet deposition to two central European forest ecosystems. Atmospheric Environment. Vol. 12:375-377.

T. A. MoMahon and P. J. Denison. 1979. Empirical atmospheric deposition parameters-A survey. Atmospheric Environment. Vol. 13:571-584.

J.L. Monteith 1973. Principles of Environmental Physics. American Elsevier Publ. Co., Inc. New York., $241 \mathrm{p}$.

C. E. Murphy Jr. 1985. Carbon dioxide and growth of a pine plantation. Forest Ecology and Management. Vol. 11:203-224. 
M. J. Owers and A. W. Powell. 1974. Deposition velocity of sulphur dioxide on land and water surfaces using a $35 \mathrm{~S}$ tracer method. Atmospheric Environment. Vol. 8:63-67.

K. Raschke. 1956. Uber die Physikalischen zwischen Warmeubergang zahl, Stahlungsaustausch, Temperatur, und Transpiration eines Blattes. Planta. Vol. 48:200-238.

SAS User's Guide: Statistics. SAS Institute. Cary, NC, USA, pp. 139-204.

G. A. Sehmel. 1980. Model predictions and a summary of dry deposition velocity data." In Atmospheric Sulfur Deposition. Eds. D. S. Shriner, C. R. Richmond, S. E. Lindberg. Ann Arbor Science, Ann Arbor, Michigan, USA, pp.223-236.

C. M. Sheih, M. L. Wesley and B. B. Hicks. 1979. Estimated dry deposition velocity of sulfur over the Eastern United States and surrounding regions. Atmospheric Environment. Vol. 13:1361-1368.

D. S. Shriner and G. S. Henderson. 1978. Sulfur distribution and cycling in a deciduous forest. J. Environmental quality. Vol. 7: 392-397.

W. H. Smith. 1981. Air Pollution and Forests. Springer-Verlag, Heidelberg, 379 p.

R. Zeisler, J. K. Langland, and S. H. Harrison. 1983. Cryogenic homogenization of biological tissue. Analytical Chemistry. Vol. 55: 2431-2434. 


\begin{tabular}{|c|c|c|c|c|c|c|}
\hline Activity & Activity & Specific & Estimated $\star$ & Estimated & Estimated & 웅 \\
\hline Added At & At & Activity & Mass & Needles & Chamber & Chamber \\
\hline Entrance & Exit & Needles & Needles & Activity & Activity & Absorption \\
\hline 31000 & 2750 & 120 & 30 & 3600 & 24650 & 80 \\
\hline
\end{tabular}


Table II. Total uptake and distribution of ${ }^{35} \mathrm{~S}$ after 3 minute exposure to ${ }^{35} \mathrm{SO}_{2}$

\begin{tabular}{|c|c|c|c|c|c|c|c|c|}
\hline & Tree & $\begin{array}{l}\text { Total } \\
\text { Specific }\end{array}$ & $\begin{array}{l}\text { Standard } \\
\text { Deviation }\end{array}$ & $\begin{array}{c}\text { \% } \\
\text { Water }\end{array}$ & $\stackrel{8}{8}$ & $\frac{8}{8}$ & $\frac{8}{8}$ & $\begin{array}{c}\frac{\circ}{\partial} \\
\text { Residual }\end{array}$ \\
\hline Date & Number & $\begin{array}{l}\text { Activity } \\
\text { DPM/gm }\end{array}$ & Total & Rinse & Rinse & Extract & Extract & Tissue \\
\hline
\end{tabular}

$\begin{array}{lrrrrrrrl}3 / 2 / 84 & 1 & 85.2 & 18.8 & 46 & 54 & 32 & 30 & 38 \\ 3 / 3 / 84 & 2 & 86.3 & 24.0 & 35 & 65 & 27 & 44 & 29 \\ 4 / 30 / 84 & 3 & 83.0 & 9.4 & 51 & 49 & 30 & 32 & 37 \\ 4 / 30 / 84 & 4 & 83.0 & 9.1 & 43 & 57 & 23 & 26 & 51 \\ 5 / 22 / 84 & 5 & 117.8 & 15.1 & 35 & 65 & 30 & 33 & 36 \\ 5 / 24 / 84 & 6 & 174.2 & 49.9 & 63 & 37 & 15 & 15 & 70 \\ 6 / 26 / 84 & 7 & 448.8 & 505.2 & 88 & 12 & 34 & 25 & 40 \\ 6 / 27 / 84 & 8 & 216.8 & 183.7 & 75 & 25 & 31 & 35 & 34 \\ 7 / 20 / 84 & 9 & 147.1 & 47.0 & 67 & 33 & & & \\ 7 / 23 / 84 & 10 & 153.0 & 52.0 & 62 & 38 & & & \\ 8 / 29 / 84 & 11 & 106.2 & 30.8 & 52 & 48 & 34 & 33 & 33 \\ 8 / 30 / 84 & 12 & 94.1 & 9.2 & 46 & 54 & 34 & 32 & 33 \\ 9 / 26 / 84 & 13 & 81.0 & 13.2 & 44 & 56 & 33 & 33 & 34 \\ 9 / 27 / 84 & 14 & 77.8 & 5.8 & 45 & 55 & 38 & 31 & 32 \\ 10 / 25 / 8 & 15 & 67.6 & 5.7 & 43 & 57 & & & \\ 10 / 26 / 8 & 16 & 69.3 & 7.9 & 41 & 59 & & & \\ 11 / 27 / 8 & 17 & 63.7 & 8.0 & 39 & 61 & & & \\ 11 / 30 / 8 & 18 & 62.0 & 4.3 & 38 & 62 & & & \\ 12 / 17 / 8 & 19 & 152.3 & 19.5 & 45 & 55 & & & \\ 12 / 18 / 8 & 20 & 142.5 & 15.0 & 44 & 56 & & 33 & 34 \\ 1 / 22 / 85 & 21 & 105.9 & 12.8 & 51 & 49 & 33 & 31 & 32 \\ 1 / 23 / 85 & 22 & 83.9 & 7.2 & 40 & 60 & 36 & 31 \\ 2 / 25 / 85 & 23 & 89.3 & 13.5 & 45 & 55 & 33 & 33 & 34 \\ 2 / 27 / 85 & 24 & 81.4 & 7.2 & 42 & 58 & 34 & 31 & 34\end{array}$


Table III. Needle deposition velocities and surface resistances calculated from $35 \mathrm{SO}_{2}$ exposure data.

$\begin{array}{lccccccc}\begin{array}{c}\text { Date } \\ \text { of }\end{array} & \begin{array}{c}\text { Tree } \\ \text { Exposure }\end{array} & \begin{array}{c}\text { Deposition } \\ \text { Velocity } \\ \mathrm{m} / \mathrm{s}\end{array} & \begin{array}{c}\mathrm{V}_{\mathrm{d}} \\ \text { Standard } \\ \text { Deviation }\end{array} & \begin{array}{c}\text { Needle } \\ \text { Resistance } \\ \mathrm{s} / \mathrm{m}\end{array} & \begin{array}{c}\mathrm{r}_{\mathrm{S}} \\ \text { Standard } \\ \text { Deviation }\end{array} & \begin{array}{c}\text { Estimated Ratio } \\ \text { Needle } \\ \mathrm{s} / \mathrm{m}\end{array} & \begin{array}{l}\text { Actual/ } \\ \text { Est. }\end{array} \\ 3 / 2 / 84 & \mathrm{~g} & 0.00050 & 0.000059 & 2750 & 10720 & 1760 & 1.56 \\ 3 / 3 / 84 & 2 & 0.00051 & 0.000141 & 2180 & 10860 & 1710 & 1.27 \\ 4 / 30 / 84 & 3 & 0.00052 & 0.000136 & 2680 & 8630 & 3690 & 0.73 \\ 4 / 30 / 84 & 4 & 0.00049 & 0.000044 & 2600 & 18430 & 3690 & 0.70 \\ 5 / 22 / 84 & 5 & 0.00071 & 0.000100 & 1230 & 21990 & 3480 & 0.35 \\ 5 / 24 / 84 & 6 & 0.00037 & 0.000150 & 5410 & 13620 & 2430 & 2.23 \\ 6 / 26 / 84 & 7 & 0.00023 & 0.000045 & 7550 & 27530 & 3630 & 2.08 \\ 6 / 27 / 84 & 8 & 0.00024 & 0.000047 & 22510 & 23030 & 4710 & 4.78 \\ 7 / 20 / 84 & 9 & 0.00040 & 0.000109 & 8490 & 11830 & 4970 & 1.71 \\ 7 / 23 / 84 & 10 & 0.00043 & 0.000047 & 4240 & 18490 & 4490 & 0: 94 \\ 8 / 29 / 84 & 11 & 0.00061 & 0.000158 & 2000 & 7170 & 4650 & 0.43 \\ 8 / 30 / 84 & 12 & 0.00063 & 0.000095 & 1790 & 7750 & 2680 & 0.67 \\ 9 / 26 / 84 & 13 & 0.00058 & 0.000061 & 2050 & 7800 & 2300 & 0.89 \\ 9 / 27 / 84 & 14 & 0.00054 & 0.000044 & 2250 & 18170 & 3430 & 0.66 \\ 10 / 25 / 84 & 15 & 0.00052 & 0.000027 & 2370 & 18660 & 1710 & 1.39 \\ 10 / 26 / 84 & 16 & 0.00051 & 0.000046 & 2340 & 15240 & 1710 & 1.37 \\ 11 / 27 / 84 & 17 & 0.00050 & 0.000057 & 2270 & 14630 & 2470 & 0.92 \\ 11 / 30 / 84 & 18 & 0.00047 & 0.000040 & 2480 & 23980 & 1710 & 1.45 \\ 12 / 17 / 84 & 19 & 0.00049 & 0.000035 & 2620 & 27890 & 1710 & 1.53 \\ 12 / 18 / 84 & 20 & 0.00045 & 0.000027 & 2850 & 33480 & 1710 & 1.67 \\ 1 / 22 / 85 & 21 & 0.00060 & 0.000042 & 2150 & 15020 & 3970 & 0.54 \\ 1 / 23 / 85 & 22 & 0.00051 & 0.000027 & 2220 & 99900 & 4070 & 0.55 \\ 2 / 25 / 85 & 23 & 0.00054 & 0.000046 & 2270 & 37780 & 3220 & 0.70 \\ 2 / 27 / 85 & 24 & 0.00047 & 0.000044 & 2630 & 19810 & 3850 & 0.68\end{array}$




\section{Figure Captions}

Figure 1. Seasonal variation of the ratio of activity in water rinse and activity left in needles after rinse. The lines are hand drawn through the mean of the two trees sampled in each month.

Figure 2. Comparison of pine plantation $\mathrm{SO}_{2}$ deposition velocity measured with the gradient and the ${ }^{35} \mathrm{SO}_{2}$ methods. Vertical line denote one standard deviation of measurements during any month. 
Figure 1. Uptake Ratios for 35-5O-2

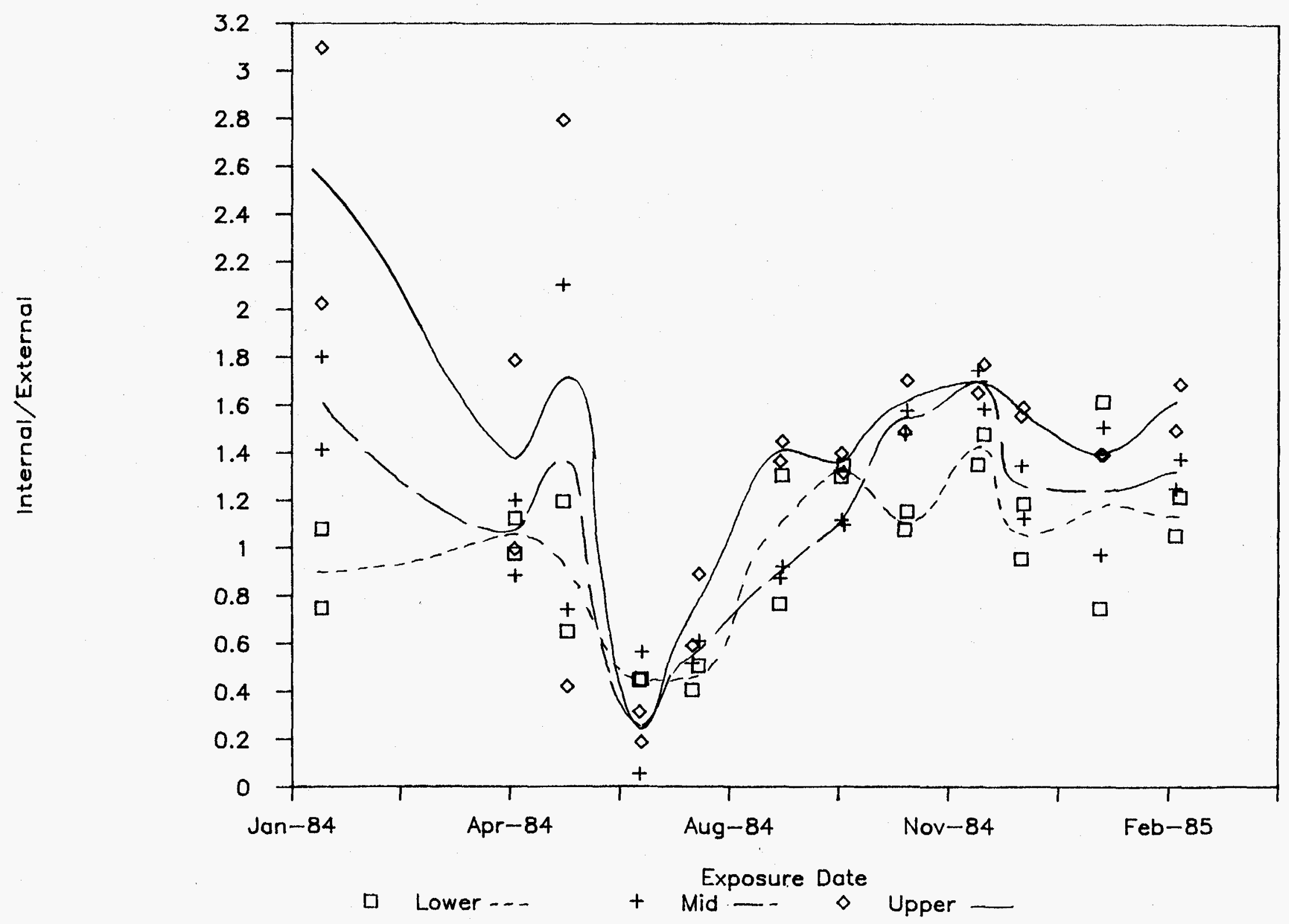




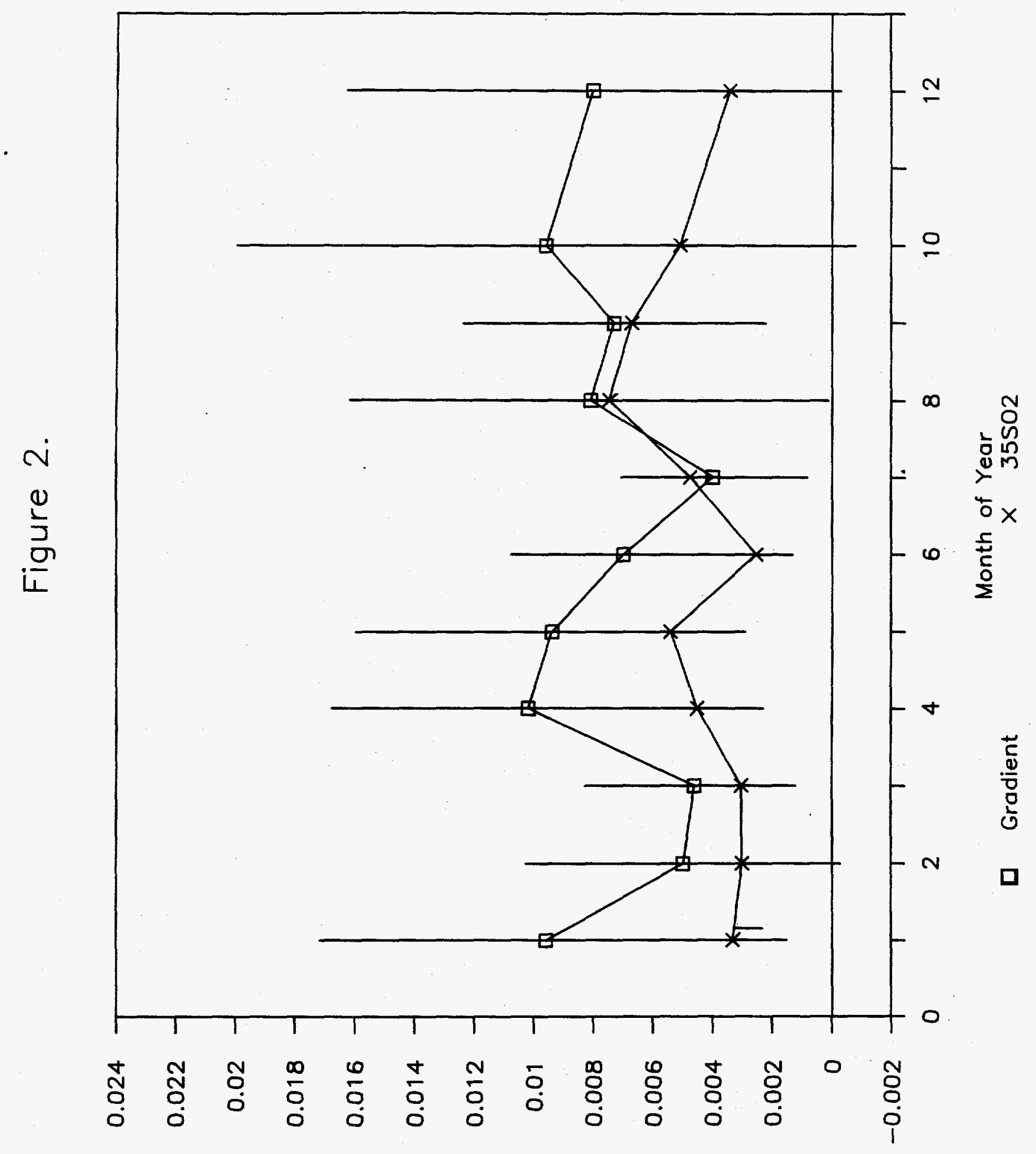

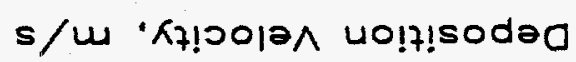

